\title{
Google Trends Youtube Access Keyword Comparison Between In Medan
}

\author{
Iman Nuel Zai \\ \{Imanzai07@gmail.com\} \\ Postgraduate Program, Pelita Kebenaran School of Theology
}

\begin{abstract}
The advancement of technology has produced a platform called YouTube, the platform for watching this video has been favored by many people. However, there are interesting things on this platform, there is a keyword search for the word porn in it. This is known by using Google trends, through this research appears on porn keywords and Christianity which if compared to which are the most accessed, especially for the people of Medan. through the Google trends, the results are that the people of Medan access more the word porn, while the Christian word is very low, this is based on data from January 1, 2018 - January 12, 2019. This is certainly very surprising, because this comparison raises an assumption that Christians need to be nurtured and given teaching and understanding of the dangers of watching pornographic films, because in the Christian faith this is very contested.
\end{abstract}

Keywords: YouTube, Google Trends, porn, Christian.

\section{Introduction}

The development of technology is not unusual for humans, this is because humans in ancient times are used to finding things that are beyond human reason in general. Even though the impact of technology is a lot of negative things and also positive things that humans get. The purpose, becomes a motive that directs the use of technology whether to be good or bad. One of the technologies that is becoming a trend now is that YouTube, platforms or websites are very loved by generations $\mathrm{X}, \mathrm{Y}$ and $\mathrm{Z}$. According to data written by BBC, YouTube is clicked on as many as 2 billion per day where this article was written in 2010 ago assuming an increase in the following years. The interesting thing about the YouTube platform is that information sharing is easier, not limited by time and place, wherever and whenever while still connected to the internet and there is no blocking from the country where the individual is, then YouTube can be accessed easily and information can be obtained quickly. Presentation of content on the YouTube platform created or uploaded by creators, but the freedom and difference of culture becomes a negative impact caused by YouTube, especially for Indonesians who have high cultural cultures and norms, as well as every religious individual, making pornographic YouTube content a taboo thing. The actions of creators who upload pornographic videos are prohibited for the Indonesian perspective, Regardless of whether the creator's place of residence is a common thing or the creator deliberately uploads it with various possibilities, this action is of course very much making YouTube a site that should be watched out for. Especially for Indonesian YouTube viewers who are Christians, this is something that deserves emphasis that it must be shunned and should not be watched, because in the perspective of the Christian faith, watching porn is a sin, and things that are forbidden by God's Word. Another problem is that in Christian circles it can happen that the availability of easy access to video content is a threat to their lives, namely in terms of holiness and purity. 
Regarding the search for content on the internet, both on search engines like Google and YouTube, it is done based on the words used. Internet users usually type one or several words according to what he is looking for, then Google or YouTube raises suggestions in the form of a list of sites or content that is suspected to be in accordance with what is sought by users. Thus the way to connect between the user and what he is looking for is a word that is typed as a search pedestal, which is called a keyword or keyword. Based on this case the question arises, is it really key words related to pornographic content. much accessed by Indonesian people? Or more narrowly is the keyword porn often accessed by the community, especially the city of Medan? what is the comparison if the porn keyword is compared to the Christian keyword?

\section{Theoretical study}

\subsection{Christian perspective about watching porn}

Through the three verses above it is clear and certain that watching porn is a sin in Christianity. The words used in Hebrew are zanah and na'af (for those who are married), which if interpreted into Indonesian means adultery and prostitution, while in Greek use the words porne/pronos and moikheia (for those who are married). In Christianity watching porn is strictly prohibited, this is based on the 7th commandment in Exodus 20:14, saying: "do not commit adultery". The word adultery covers a broad range, in its interpretation the word "do not commit adultery" is included in the category of watching and doing. In Matthew 5:28, note that just looking at and giving rise to desire is included in sin, said this desire can include lust and desire to have sex. And when a Christian watches a pornographic film and wants to do it and raises lust, then the individual has committed adultery, and committed adultery in the law given by God through Moses, that is sin. Why is it sin? Because it is stated in 1 Corinthians 6: 19-20.

\subsection{YouTube}

YouTube was founded by three people, they are Steve Chen, Jawed Karim, and Chad Hurley who started in February 2005, the three of them are workers at Paypal, where after they got an investment from Sequola Capital of USD 11.5 million, YouTube became a technology startup platform, which was acquired by Google in 2006. Where the first video uploaded was titled "Me at the zoo", on April 23, 2005 it was located at the San Diego zoo, which aired one of the founders of YouTube named Jawed Karim with the Jawed account name. YouTube is a platform that provides a variety of content in the form of video that is quite interesting, where the content is divided into various categories, such as:

\begin{tabular}{|c|c|}
\hline News \& politics & Music \\
\hline Blog \& people & Nonprofit \& activism \\
\hline Way \& style & Sports \\
\hline Film \& animation & Education \\
\hline Game & Travel \& events \\
\hline Pet & Science \& technology \\
\hline Entertainment & Comedy \\
\hline Cars \& automotive & \\
\hline
\end{tabular}

Fig. 1. Categories on the YouTube Platform 
In the YouTube system there are three important things that need to be known, that the video is related to the viewer and the viewer is related to advertising, and ads related to video. There is a cycle of rotation that is mutually binding from these three parts, can be seen through the picture below.

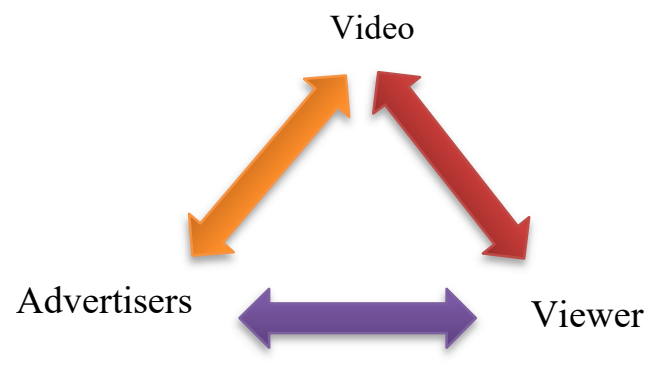

Fig.2. Three Important Cycles in YouTube

But there is one thing that is quite interesting from this, that there is a rule that YouTube has given on their platform for all creators who upload videos. That is the age restriction regulation, which says that: "videos that are exposed to or intentionally activated by creators in terms of age restrictions will not be accessible for those who do not have an account, activate a limited model, and are under 18 years of age." When searching for information, there is no information that has been obtained for sure since when the age restriction feature and age under 18 years old was launched by the YouTube platform, but for the limited model launched since 2010 where YouTube gives reasons, this feature or model functions as a controller and limiting access to adult content or not child-friendly, and this is very suitable for children, institutions, schools and libraries. Through this we can draw the conclusion that before YouTube was a website where the creators were free to upload their videos without thinking that there were children watching the video. While the second conclusion, that on the YouTube platform there is still content that is adult in nature and contains things that are culturally in Indonesia that is something that is not worth watching.

There are four points YouTube emphasizes in evaluating content compatibility for all ages:

$$
\begin{array}{|l|}
\hline \text { Violence and disturbing images } \\
\hline \text { Vulgar language } \\
\hline \text { Dangerous and risky activities } \\
\hline \text { Nudity and sexual content } \\
\hline
\end{array}
$$

Fig. 3. Four Content Match Evaluation Points

\section{Method}

The method used in the comparison of keywords between porn and Christianity, using a website owned by Google called Google trends, while the website with the name Google Trends was founded in 2006, where the goal is to provide a map and statistics to sellers in seeing interest which is sought after through the Google search engine, the development of time, Google trends are 
also used to see a lot of interest sought on the YouTube platform. The method used in the calculation is to divide each region and geography, then measure with a range through 0-100.

\section{Analysis}

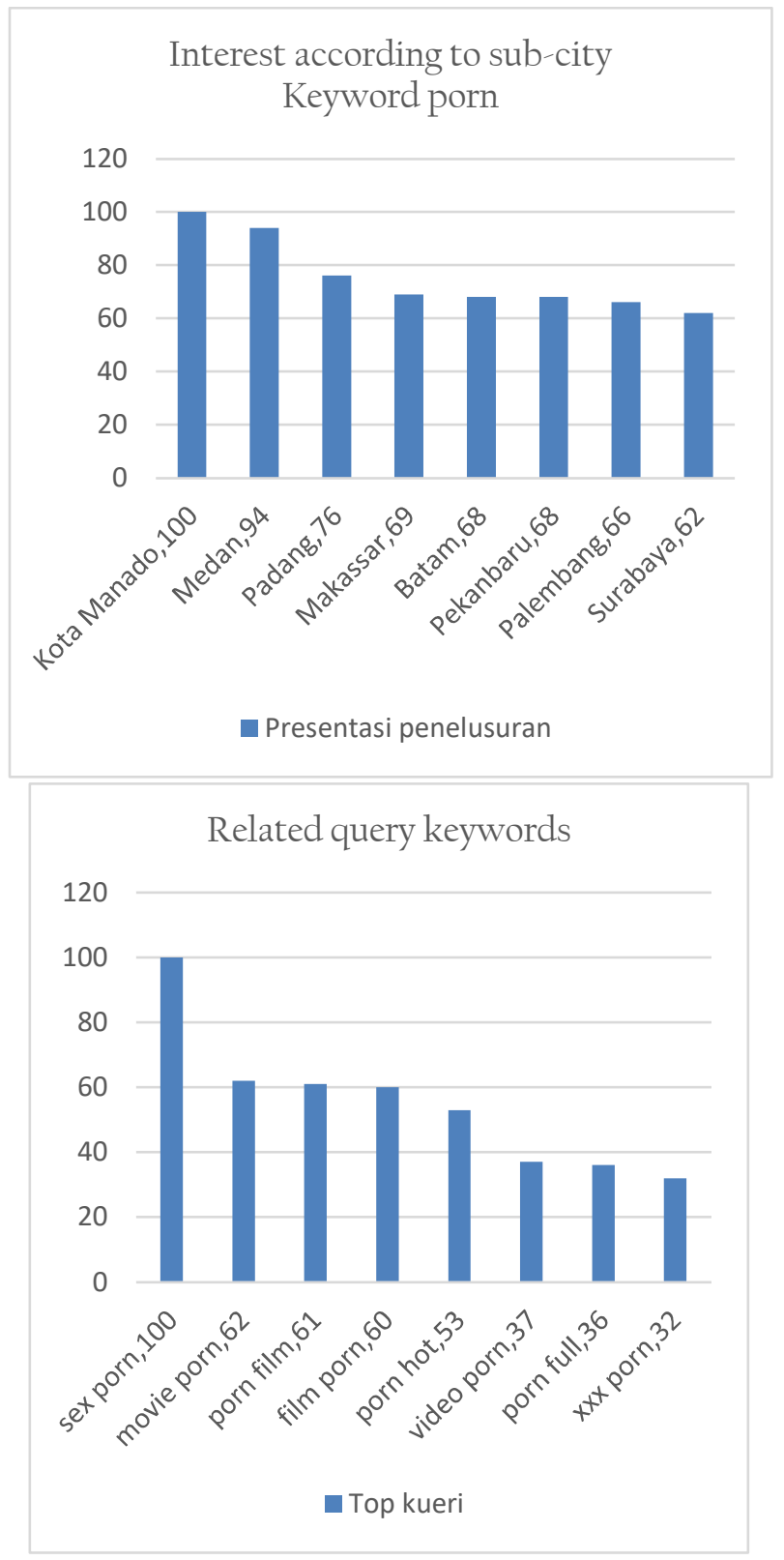

Fig. 4. Sub-city Search Graph and Query Keywords during 01 January 2018 - 12 January 2019 
Through the graph above, where the range of 0-100 (scale), 100 indicates the highest search level in the region, and if 50 shows the level of popularity is partly or low. Through Google Trends keyword porn, according to sub-cities in the field have as much as $94 \%$ interest in second place in Indonesia which shows almost all users of the city of Medan on the YouTube platform access this keyword. And according to the calculation of top queries like the graph above, the keyword sex porn is a keyword that is often accessed and is a favorite of users on the YouTube platform by $100 \%$ maximum. Through the data provided by the Google trends above, of course this is very surprising. Because according to the percentage data the population of Christians in 2016 is $21.16 \%$ and according to Rubbrikkristen.com the number of Sumatran Christians in 2017 is $31.00 \%$ and there is certainly an increase back in 2018. Surely this is very surprising, because it is done back in comparison of keywords namely porn and Christianity, which ones are the most accessed? Note the chart below based on data from Google trends.

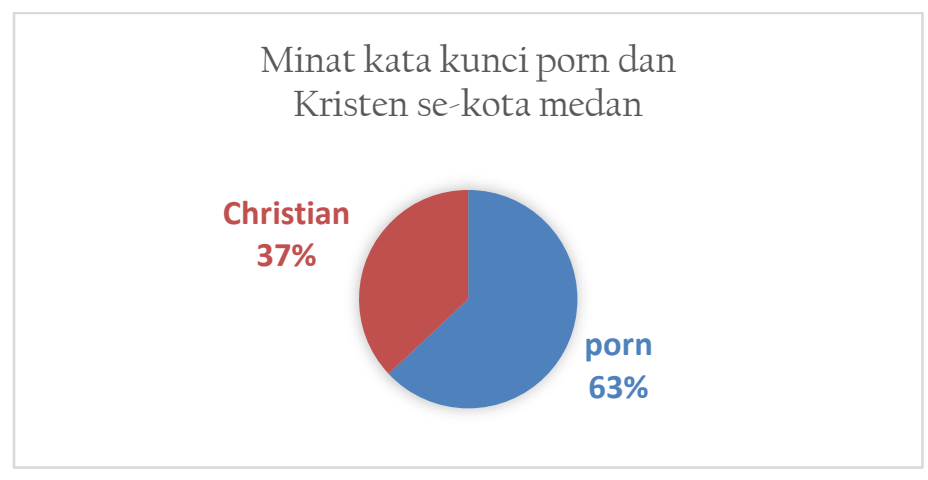

Fig.5. Graph of Christian and Porn Keyword Search Comparison Medan subcity during 01 January 2018 - 12 January 2019

\section{Results}

Through the Google Trends data above, the calculation according to sub-cities in Indonesia, Medan City is ranked 2nd with a percentage of $94 \%$ accessing porn keywords during vulnerable January 012018 - January 12 2019. Through Google trends data above shows that the word the key to Christianity with the assumption that access is not only Christian people is $37 \%$ smaller than the word porn by $63 \%$ on a $0-100$ scale maximum, where the population in North Sumatra in 2017 was based on rubbrikkristen.com at 31\% assuming an increase in in 2018, it showed that interest in Christian keywords on the YouTube platform was very low, and porn keywords were accessed more by $63 \%$ assuming that Christians also access these keywords, in the city area of Medan. so that in accordance with the question in the introduction, "what is the comparison if the porn keyword is compared to the Christian keyword?" then the results are found that in Medan city accessing the word porn is $63 \%$ (assuming Christians have access to it) and keywords related to Christianity only 37\% (assuming that not only Christians), so it can be concluded that Christians have an interest in accessing porn-related keywords and watching them flout the YouTube platform. 


\section{Conclusion}

Based on the data above, the church should provide teaching on the sinfulness and the risks of watching pornographic films by explaining the verses of the Word of God that discuss this. Seminar and teaching is held for the congregation and also toe create and publish tracts and books that discuss the danger of watching porn for Christians. Advertisements can be made when asked for church news, about the dangers and contain sins in watching porn videos. The creation of a short Christian nuance film about the dangers of porn.

\section{References}

[1] https://www.bbc.com/indonesia/majalah/2010/05/100517_YouTube

[2] Terjemahan Baru-Lembaga Alkitab Indonesia (TB-LAI)

[3] https://www.google.com/amp/m.merdeka.com/amp/teknologi/sejarah-singkat-YouTube -situsvideo-sharing-terbesar-tekstory.html

[4] https://support.google.com/YouTube /answer/2802167?hl=id

[5] https://support.google.com/YouTube /answer/7354993?hl=id

[6] https://trends.google.co.id/trends/explore?geo=ID\&gprop=YouTube \&q=porn

[7] https://id.wikipedia.org/wiki/Kota_Medan\#cite_note-id.scribd.com-26

[8] https://rubrikkristen.com/10-provinsi-di-indonesia-dengan-persentase-kristen-tertinggi/

[9] https://trends.google.co.id/trends/explore?geo=ID\&gprop=YouTube \&q=porn,kristen 